\title{
Mineros. La caravana Del hambre
}

\author{
José Rivera Castro* \\ A Rolande Trempé
}

\section{Resumen}

A partir de la recuperación de una documentación excepcional sobre la huelga minera de 1950-51, en Coahuila, y sobre la marcha de cerca de cuatro mil trabajadores de esos centros mineros hasta la ciudad de México, se busca mostrar los esfuerzos de un movimiento obrero decidido a mantener sus derechos laborales frente a poderosos consorcios industriales y frente a un Estado cada vez más controlador. La "Caravana del hambre", como se conoció a este movimiento, representa una de las manifestaciones de resistencia más importantes de la clase obrera mexicana durante el siglo veinte.

Palabras claves: Movimiento obrero, conflicto minero, control sindical, huelga.

\begin{abstract}
As of the recovery of outstanding documentation about the miner strike of 1950-51, in Coahuila, and on the protest of around four thousand workers from those mining centers to Mexico city, seeks to show the efforts of a worker movement determined to maintain their labor rights against powerful industrial consortia and against of an increasingly controlling government. The "Hunger Caravan", as this movement was known, represents one of the more important manifestations of resistance of the mexican working class during the 20th Century.
\end{abstract}

Keywords: working class movement, miner conflict, union control, strike.

\footnotetext{
* Profesor-investigador de la UAM-Iztapalapa; river@prodigy.net.mx; rive@xanum.uam.mx
} 
La "Caravana del hambre" es uno de los movimientos sociales de resistencia más importantes que se han expresado en la clase obrera durante el siglo veinte. Es un conflicto que se originó en enero de 1951 en la región carbonífera de Coahuila. Surgió en una época en que grandes empresas estadounidenses atravesaban muy buena situación productiva y de ganancias. A ello se agregaba un periodo de estabilización política en el que el Estado necesitaba disminuir el peso y las presiones de los sindicatos, ello quería decir, evitar la manifestación obrera fuera de los discursos de la clase gobernante y de las estructuras de poder dominante.

En estas páginas me propongo tratar uno de los conflictos mineros más largos y difíciles que ha vivido la clase obrera de nuestro país. La industria minera atravesaba intensos problemas provocados fundamentalmente por las malas condiciones laborales. La minería es uno de los espacios de trabajo donde han sucedido diariamente accidentes. La falta de seguridad y de servicios médicos han producido enfermedades y muchas muertes. Los trabajadores han tenido que preparar la organización y la lucha para transformar su vida cotidiana dentro de los centros laborales. Es conocida la impunidad y las faltas de respeto extranjeras, que han infringido las normas legales.

Como antecedente sindical cercano debemos recordar la formación del Sindicato Nacional Minero y su propuesta de un contrato colectivo único que amparara a todos los trabajadores de esta industria. El objetivo era que todas las empresas de este ramo se rigieran con las mismas normas de contratación. Se preparó un pliego petitorio laboral que prácticamente no fue atendido, situación que produjo una huelga general en 1944. Participaron trabajadores de más de cien empresas que incluían a las productoras de plata, oro, hierro, cobre y otros metales de los principales centros mineros, así como de las ciudades de Monterrey, Torreón y Piedras Negras.

\section{El escenario económico. La industrialización}

A partir de los años cuarenta del siglo veinte, concretamente con la llegada a la presidencia de México de Miguel Alemán en 1946, se aceleró el proyecto de crecimiento económico que había iniciado el general Manuel Ávila Camacho y que se caracterizó por instaurar una política de desarrollo a largo 
plazo en torno a la industrialización en la que el Estado debía jugar un papel fundamental. La debilidad de la industria y del empresariado llevó al Estado a extender y diversificar la actividad económica. Alemán se propuso elevar considerablemente las tasas de interés, de ahorro e inversión, aumentar la productividad de los gastos gubernamentales y disminuir, mediante políticas inflacionarias, la participación de los trabajadores en el ingreso, así como acelerar el proceso de incorporación estatal de los sindicatos industriales. ${ }^{1}$

La década de los cuarenta fue un periodo de enormes y profundos cambios. Se modificó el patrón de acumulación y las estructuras políticas experimentaron transformaciones decisivas, fundamentalmente en las relaciones entre el Estado y las agrupaciones de masas. Este proceso se insertó en un conjunto de luchas sociales y políticas. ${ }^{2}$ La acción del Estado frente a los grandes sindicatos estuvo encaminada a debilitar y someter la resistencia obrera a las necesidades y exigencias de la industrialización y del régimen político. ${ }^{3}$ Las grandes centrales obreras, como la CTM, atravesaron un periodo de crisis por la rivalidad y los enfrentamientos entre los distintos bandos. El gobierno se acostumbró a ejercer una interferencia constante que obstaculizaba el desarrollo interno; se acentuó la corrupción, el oportunismo y la codicia de muchos líderes por los cargos propuestos por el partido oficial. El campo quedó libre para Fidel Velázquez cuando se expulsó a cuadros y dirigentes sindicales. En plena guerra fría, la CTM quedó uncida a la política de Miguel Alemán; y el gobierno había creado poco antes, en 1941, el delito de disolución social que se aplicó más tarde a los dirigentes independientes para frenar movimientos disidentes. ${ }^{4} \mathrm{La}$ forma en que se asumió el control sobre los obreros recibió el nombre de charrismo sindical, fenómeno inicialmente ligado a diversas empresas como PEMEX, las ferrocarrileras y mineras.

La subordinación obrera se convirtió en una de las líneas maestras para respaldar la estrategia estatal de la industrialización, al menos en tres aspectos: a) la estabilidad política y el apoyo organizado al Estado en sus conflictos con otros grupos sociales; b)la posibilidad de una caída drástica

1 Ayala, Estado y desarrollo, p. 248.

2 Durán, "Economía política", pp. 563-584.

3 Ibid., p. 564.

4 Mussot y González, “En la posguerra”, pp. 181-251. 
del salario real que mejoró las condiciones de rentabilidad del capital privado sin que simultáneamente creciera la inestabilidad social; c) la convergencia de los dos puntos anteriores ayudó notablemente a configurar un ambiente propicio para el desarrollo del capital privado. ${ }^{5}$

\section{Los mineros}

Debemos señalar algunos aspectos que provocaron el malestar de los trabajadores mineros. En 1948, estos habían realizado un pacto con los ferrocarrileros y los petroleros. Estaban influidos por la corriente política del lombardismo. Más tarde, el gobierno intervino en la sexta Convención Ordinaria del sindicato minero. Activistas ligados al gobierno de Miguel Alemán intervinieron en las sesiones. Se impuso a delegados falsos, no se acreditó a los verdaderos representantes mineros, violando los estatutos de las agrupaciones y fue impuesto un secretario general para todo el sindicato. Varias secciones del área carbonífera se opusieron a la intromisión gubernamental. Hay que destacar también que había descontento obrero como consecuencia de una política de reorganización empresarial en esa zona, aumento de la inseguridad en las minas, despidos, cambios de categorías, modificación de las formas de pago, etcétera. ${ }^{6}$

Los mineros de Nueva Rosita y de Cloete respondieron con una huelga larga que fue declarada ilegal y quedaron despedidos varios miles de trabajadores. De ahí surgió la idea de realizar una caravana hasta la ciudad de México. ${ }^{7}$

En enero de 1951 un grupo de intelectuales, miembros de la Sociedad de Estudios Mexicanos (SEM), elaboraron un documento al que denominaron "25 verdades sobre la cuestión minera". Entre los firmantes se encontraban

5 Ayala, Estado y desarrollo, pp. 262-263.

6 Sariego y otros, El Estado y la minería, p. 243.

7 Ibid., p. 243.

8 La Sociedad de Estudios Mexicanos, "25 verdades sobre la cuestión mexicana", México, enero de 1951, p. 2. Este documento se encuentra en el Archivo General de la Nación. Dirección de Investigaciones Políticas y Sociales (en adelante AGN, DIPS), 2-1/331/7, vol. 287, exp. 45, 112 fs. Este expediente y el que le continúa (AGN, DIPS, 2-1/331/7, vol. 288, exp. 9, 425 fs.) son la base documental sobre la que se elaboró este trabajo. 
los hermanos Ángel y Narciso Bassols Batalla, Elí de Gortari, Francisco López Cámara, Fernando Rosenzweig, Joaquín McGregor y varias personalidades más.

Esta agrupación organizó un ciclo de conferencias sobre la cuestión minera, actos que se realizaron en el local de la Asociación Mexicana de Periodistas en el Distrito Federal. Los ponentes destacaban que el primer paso para la resolución de los problemas nacionales consistía en la discusión abierta y democrática de su planteamiento correcto. La SEM envió a dos de sus miembros a la zona de Palau y Nueva Rosita con el objetivo de llevar a los mineros un mensaje de aliento, y de solidaridad y de recoger en el lugar de los hechos información suficiente para formular una denuncia vigorosa y fundamentada de la situación angustiosa en que se realizaba su lucha. Poco después, otro de los miembros de la SEM fue expulsado de la región minera cuando intentaba continuar ese estudio. ${ }^{9}$ A continuación, elaboramos una síntesis de los principales aspectos tratados en el documento citado.

1. A partir del 25 de septiembre de 1950, mil trescientos mineros de Palau y setecientos de Cloete estallaron la huelga defendiendo sus derechos sindicales. El consiguiente descenso de la producción de carbón puso en peligro a la industria siderúrgica y al proceso de industrialización del país. ${ }^{10}$

2. El espíritu de los mineros había sido magnífico durante la huelga. Acompañados por sus familiares, habían resistido una presión muy fuerte: se clausuraron las cooperativas obreras, se congelaron los fondos sindicales, el ejército ocupó las poblaciones mineras y se apoderaron de los locales de los huelguistas, en las escuelas se habían negado a recibir a los hijos de los mineros y se había impedido el acceso de las familias obreras a las clínicas. ${ }^{11}$

3. Hubo una presión militar sobre los huelguistas, pero estos se mantuvieron dentro de los más rigurosos límites legales neutralizando al ejército. ${ }^{12}$

9 Idem.

10 Ibid., p. 4.

11 Idem.

12 Idem. 
4. Se dio un descontento popular y una rebeldía general frente a las condiciones de vida inhumanas e insoportables. Se procuró que no hubiera gente extraña a los mineros. La solidaridad y simpatía exterior se expresaron con mucho cuidado para evitar calumnias a los trabajadores. ${ }^{13}$

5. Hubo un hecho importante en relación con el aviso que la Compañía Carbonífera Unida de Palau s. A. recibió de que la sección 28 del sindicato minero estallaría la huelga el 25 de septiembre. Sus funcionarios manifestaron disposición para llegar a un entendimiento. Inmediatamente el titular de la Secretaría del Trabajo hizo saber, a la Junta Federal de Sabinas y a la Compañía Carbonífera, que el comité ejecutivo de la sección 28 había quedado suspendido en sus funciones, con lo cual se evitó un posible acuerdo entre trabajadores y empresarios. ${ }^{14}$

6. La Secretaría del Trabajo no reconoció la decisión obrera del estallido huelguístico en las minas de Palau. ${ }^{15}$

7. Antes del estallido de la huelga en Nueva Rosita y Cloete (16 de octubre), los funcionarios de la Secretaría del Trabajo declararon que sería una huelga "inexistente". ${ }^{16}$

8. A diferencia de la huelga de Palau, que se originó por la revisión normal del contrato colectivo, el conflicto de Nueva Rosita y Cloete se produjo por las violaciones empresariales a los contratos colectivos. En los dos casos, la Secretaría del Trabajo impidió el trato entre los patrones y los mineros. ${ }^{17}$

9. Cuando estallaron los conflictos, los funcionarios de la Secretaría del Trabajo intentaron obligar a los sindicatos solidarios con la huelga a reconocer al sindicato nacional nombrado y manejado por el gobierno. ${ }^{18}$

13 Idem.

14 Idem.

15 Ibid., p. 5.

16 Idem.

17 Idem.

18 Idem. 
10. La Secretaría del Trabajo se convirtió en una instancia provocadora de problemas y de intromisión en la vida sindical. ${ }^{19}$

11. El sindicato impuesto por el gobierno ha servido para despojar de toda personalidad jurídica a los representantes escogidos libremente por los trabajadores. ${ }^{20}$

12. El gobierno le ha dado un trato al conflicto huelguístico de "abandono de trabajo" y le ha negado a los trabajadores los derechos de asociación, representación y contratación que las leyes del trabajo les garantizan, con el objeto de romper la huelga. ${ }^{21}$

13 y 14. El gobierno ha permitido a las empresas mineras la contratación de trabajadores del exterior. Los patrones han quedado automáticamente en libertad para romper los contratos de trabajo y dar ocupación a quien mande su voluntad. El gobierno ha manejado según sus propias opiniones la interpretación de las leyes laborales, comportamiento que originó el control de las directivas sindicales. La idea es tener en sus manos el manejo de los liderazgos obreros. ${ }^{22}$

15 y 16 . Se ha realizado una amplia campaña contra los mineros huelguistas, se ha difamado y se ha tratado de desprestigiar a los obreros. Se ha dicho que es el "comunismo subversivo y perturbador el responsable de la huelga minera". ${ }^{23}$

17 y 18. Se preparó un clima de información sobre la huelga, propicio para llevar adelante una política violenta contra los trabajadores. Se inventó el "origen comunista del conflicto". Se ha hablado de la actividad de agitadores que piensan recurrir a la violencia. El gobierno difundió información falsa y el ejército intervino en Nueva Rosita y Palau. ${ }^{24}$

19. La inexactitud de la información periodística ha intentado distanciar a los trabajadores de sus dirigentes, predisponer el ánimo del

19 Idem.

$20 \mathrm{Idem}$.

21 Idem.

22 Ibid., p. 6.

23 Idem.

24 Idem. 
presidente Miguel Alemán contra los huelguistas y lanzar al ejército contra los mineros. ${ }^{25}$

20. Permanentemente la mayoría de los periódicos ha difundido que el conflicto minero había terminado. ${ }^{26}$

21. Desde el momento en que Pedro Ramírez Vázquez fue designado como Secretario del Trabajo, se inició una política encaminada a reducir a la clase obrera a una simple fuerza de trabajo al servicio de un desarrollo económico cuyos beneficios se destinaban exclusivamente a los inversionistas estadounidenses y a los grupos de capital financiero mexicano que subordinaban su concepto de patria y de bienestar público a las ganancias del empresariado. ${ }^{27}$

22. El fracaso de las nuevas direcciones sindicales ligadas al Estado, el derrumbe de la política encaminada a destruir la independencia de los grandes sindicatos nacionales de la industria, demuestra que el control mecánico de las agrupaciones, no supone la subordinación soberana de los obreros y que esta, cuando los dirigentes han claudicado, conserva los medios para manifestarse. ${ }^{28}$

23. La Secretaría del Trabajo se ha apoderado de las funciones propias de las asambleas obreras, al pretender calificar la autenticidad de las credenciales que acreditan a los delegados convencionistas y al negarse a tomar nota de las designaciones de comités ejecutivos y de la formación de nuevas centrales obreras. ${ }^{29}$

24. La Secretaría del Trabajo se ha propuesto realizar una política encaminada a burocratizar el movimiento obrero y, paralelamente a esa política, corre el designio de convertir al proletariado en apéndice del partido oficial..$^{30}$

25. La política gubernamental implica una desviación del programa de la revolución, el cual concibe el desarrollo económico del país

25 Idem.

26 Idem.

27 Ibid., p. 7.

28 Idem.

29 Idem.

$30 \mathrm{Idem}$. 
como un proceso encaminado fundamentalmente a mejorar el nivel de vida del pueblo. ${ }^{31}$

\section{La caravana}

La síntesis del texto publicado por el grupo de intelectuales anteriormente citado, es una visión conocedora de la situación laboral, las condiciones de vida, la resistencia obrera y las enormes dificultades que vivieron los mineros y su caravana. En las publicaciones e información consultadasfundamentalmente testimonios, artículos periodísticos e informes oficiales_-, se reitera la difícil realidad que exponen los miembros de la Sociedad de Estudios Mexicanos.

La "Caravana del hambre" de los mineros de Coahuila se inició el 20 de enero de 1951. Fueron cuarenta y nueve días de marcha hasta su destino: la ciudad de México. Salió de Nueva Rosita, pasó por Sabinas, Hermanas, Monclova, Villa Frontera, Castaños, Piedras Negras, Saltillo, Rinconada, Monterrey, Ciudad Victoria, Ciudad del Mante, Jacala y Tizayuca. Fueron mil cuatrocientos kilómetros, la prensa y los organizadores hablaron de una cifra entre tres mil y cuatro mil caminantes. Algunos venían con sus familias.

Los responsables de la caravana fueron Francisco Solís, Ciro Falcón, Juan Marquecho, Abdón Alfaro y Félix Cruz. La columna se integró en grupos de cincuenta personas, cada uno con su jefe de aprovisionamiento.

En la ciudad de México se formó una Comisión de Alojamiento y Finanzas encabezada por José Encinas y Marcos Rojas, para atender a los integrantes de la caravana. La comisión anunció que Vicente Lombardo Toledano daría alojamiento y comida a quinientos mineros durante todo el tiempo que fuera necesario; el senador Juan Manuel Elizondo se comprometió a alojar a cincuenta. También se anunció que la Universidad Obrera recibiría todos los que pudiesen caber en sus instalaciones. ${ }^{32}$

En los diversos estados por donde pasaron los marchistas, los gobernadores y diversos sindicatos y otras asociaciones les ofrecieron alimentos, ropa y comida. ${ }^{33}$

31 Idem.

32 La Prensa, 9 de febrero de 1951.

33 Excélsior, 26 de febrero de 1951. 
La mayoría de los sindicalistas del país estaban integrados en el sector obrero del partido oficial. Sus dirigentes se reunieron varias veces para tomar una decisión unificada con objeto de atacar a la caravana minera. Así por ejemplo, el 6 de marzo se reunieron los dirigentes de la CTM, la CROM y otras asociaciones obreras y decidieron respaldar al secretario del Trabajo y atacar a los marchistas. Incluso acordaron solicitar una visita al presidente de la República para respaldar su política frente al conflicto minero. Rigoberto González, secretario general de la CROM señaló que la caravana del hambre adoptó una actitud subversiva y que pretendía por la fuerza un cambio del comité sindical minero del país. Los representantes jurídicos del comité minero "oficial" prepararon una denuncia jurídica contra los organizadores de la caravana, ellos expresaron que se fundamentaban en la Ley Orgánica del Ministerio Público y en el Código de Procedimientos Penales. Acusaron a Agustín Guzmán Vaca, secretario general de la Unión de Obreros y Campesinos de México, a Antonio García Moreno dirigente principal de los marchistas. También a otros líderes. Todos ellos fueron acusados de fraude en la administración de las cuotas sindicales. Asimismo, fueron denunciados por propalar ideas, programas y normas de acción de gobiernos extranjeros perturbadores del orden público que afectaban a la soberanía del Estado mexicano. ${ }^{34}$

Por otra parte, la dirección sindical impuesta por el gobierno en la sección 14 de Nueva Rosita, atacaba a los marchistas, a personalidades y asociaciones que apoyaban a los mineros. Decía que era una actitud subversiva, perniciosa y que se atacaba al gobierno de Miguel Alemán. Que eran escasamente dos mil trabajadores a los que se les rescindió el contrato de trabajo y que seguramente participaban en la caravana porque habían sido engañados por falsos líderes. ${ }^{35}$

El 10 de marzo los marchistas ya se encontraban en el sitio llamado Indios Verdes en el norte de la ciudad de México. Se organizaron entre las nueve y las doce de la mañana para salir hacia el zócalo. El informe del inspector de la Secretaría de Gobernación escribió que poco a poco fueron llegando grupos de obreros de diversas fábricas, asociaciones y de

34 La Prensa, 7 de marzo de 1951. 35 Excélsior, 10 de marzo de 1951. 
instituciones educativas. El informe mencionaba que ya estaba designado un agente en el monumento a la revolución para relatar los sucesos. También se mencionaba que había dos agentes en el zócalo para recoger la información del mitin que pensaban realizar los marchistas. Dicho informe destacaba que el líder sindical Vicente Lombardo Toledano había estado en los Indios Verdes recomendando a los marchistas compostura y disciplina. En el mismo sentido, Agustín Guzmán, líder de la UGOCM, daba la bienvenida a los miembros de la caravana y les recomendaba orden y mucha calma. ${ }^{36}$

El informe del agente de Investigaciones Políticas de la Secretaría de Gobernación señaló que la caravana llegó al zócalo alrededor de las 14.30 horas del 10 de marzo de 1951. Mencionó que asistieron dirigentes de diversas asociaciones políticas y sindicales. Destacó la participación del Partido Comunista, del Partido Popular, de la Confederación de Jóvenes Mexicanos, del Partido Obrero y Campesino Mexicano y de la Unión General de Obreros y Campesinos de México. Hicieron presencia entre otros, Dionisio Encinas, Esther Chapa, Manuel Terrazas, Arnoldo Martínez Verdugo, Rodolfo Dorantes, Salvador M. Gámiz, Carlos Sánchez Cárdenas, Alberto Lumbreras, Miguel Arroche Parra, Consuelo Uranga, Agustín Guzmán, Adán Nieto, etcétera. ${ }^{37}$

Hay un relato del inspector sobre el contenido de los discursos de los oradores en el mitin. Habló María Guadalupe Rocha, integrante de la marcha, quien pidió garantías y justicia para la clase obrera, atacó a la prensa, mencionó la intromisión de los Estados Unidos en el conflicto y exigió el respeto a los derechos de los trabajadores. El minero Francisco Solís acusó directamente al secretario del Trabajo de las agresiones sufridas a lo largo de la huelga. Mencionó que el conflicto minero era un movimiento justo. Acusó a las empresas estadounidenses de violar los derechos de nuestro país, apuntó que miembros de diversas secciones se habían agregado a la caravana. Antonio García Moreno hizo un relato minucioso de la huelga, habló de una campaña periodística para desprestigiar a los mineros, contó como en 1950 el ministro del Trabajo pretendió arrebatar los derechos obreros, saboteando la sexta Convención del Sindicato Minero con pistoleros

36 "Informe sobre caravana de mineros", 1 de marzo de 1951, AGN, DIPS, 2-1/331.7, vol. 287 , exp. 45.

37 Ibid., p. 2. 
y representantes falsos investidos de facultades arbitrarias. Agradeció a los campesinos de la región lagunera y de otras zonas que ayudaron a la caravana. Destacó el apoyo de las asociaciones mineras de Estados Unidos, Canadá, China, Polonia y de Alemania (occidental y oriental). ${ }^{38}$

Una comisión de mineros acudió a Los Pinos para tramitar una cita con el presidente Miguel Alemán. Este no se encontraba en la ciudad de México y entonces comunicaron a los representantes que sería Adolfo Ruiz Cortines, secretario de Gobernación, el responsable de la comisión quien los recibiría para iniciar pláticas y poder llegar a un acuerdo. También participarían Francisco González de la Vega, titular de la Procuraduría General de la República y Eleazar Muñoz, subsecretario del Trabajo. La primera entrevista con los integrantes del comité de huelga se había efectuado el 13 de marzo en las oficinas de la Secretaría de Gobernación. De este encuentro no se dieron a conocer noticias hasta muy entrada la noche. ${ }^{39}$

Mientras tanto, Alfonso Martínez Domínguez, secretario general de la Federación Sindical de Trabajadores al Servicio del Estado (FSTSE), realizó gestiones para que se buscara otro alojamiento donde situar a los miembros de la caravana. El líder de la burocracia argumentaba que los mineros permanecían en instalaciones costosísimas (Estadio Deportivo 18 de Marzo) que podían deteriorarse y afectar los intereses de los empleados de gobierno. ${ }^{40}$

El 16 de marzo un agente de la Dirección de Investigaciones Políticas y Sociales (DIPS) de la Secretaría de Gobernación informaba al director de esa instancia sobre las actividades de los mineros en el sitio donde estaban alojados. Señalaba en primer lugar, que los marchistas se encontraban en todos los espacios construidos del campo deportivo, durante el día sus pertenencias estaban envueltas en sarapes y mantas colocados en estos lugares. Por la noche dormían en el gimnasio, en las gradas del estadio y otros diseminados en el pasto. En relación con la comida, los mineros recibían sus alimentos y leña para procesarlos por cuadrillas de diez personas, hacían fogatas y cocinaban en latas de lámina. La mayor parte de

38 Ibid., p. 3.

39 Excélsior, 14 de marzo de 1951.

40 Ibid., 15 de marzo de 1951. 
los mineros consideraba que no eran suficientes las raciones alimentarias. $\mathrm{El}$ agente continuaba su relato y contaba que después del baño, los mineros lavaban su ropa y desayunaban. Luego hacían comentarios sobre la situación del conflicto. Los mineros pensaban que la situación era muy grave, pues las empresas los podían volver a contratar pero perdiendo sus derechos de antigüedad, de escalafón y sin pagarles los salarios caídos. El comentario general era que no tenían ningún conflicto con las empresas, ni demandaban mayores salarios, sino que querían la inmediata salida del secretario del Trabajo porque consideraban ilegal la imposición de la directiva sindical. $\mathrm{El}$ informe destacaba que todos los mineros estaban desmoralizados, pues sabían que sus familias no tenían alimentos y no podían conseguirlos. El agente mencionaba que durante el tiempo de observación no vio a ningún dirigente comunista. La mayor parte de los marchistas permanecía en el parque y eran sobre todo los líderes los que salían a distintas reuniones. ${ }^{41}$

El 17 de marzo los dirigentes de la caravana organizaron un mitin en el Hemiciclo a Juárez. Un agente de la DIPs informaba sobre el acto. Mencionó que llegaron alrededor de 1,200 mineros portando a la cabeza de la manifestación dos banderas nacionales y un estandarte rojinegro. Los trabajadores se situaron de forma ordenada e inmediatamente una comisión de sindicatos textiles entregó a los huelguistas una cantidad de dinero para los gastos. ${ }^{42}$

En este mismo informe se hace una crónica de la participación de tres oradores en la reunión pública. Máximo Vera Portales se encargó de explicar los motivos de la caravana, así como el camino recorrido a pesar de la actitud de los líderes "charros" y del secretario del Trabajo, que habían intentado domesticar a los obreros de la marcha. Los funcionarios de la Secretaría del Trabajo han tratado injustamente los ideales de los trabajadores. ${ }^{43} \mathrm{El}$ agente continúa su relato sobre el primer orador:

Dice que son hombres y que estarán pacientes, enérgicos ante los verdugos del despotismo, porque un pueblo de aspiraciones libres como México, no

41 "Información sobre marchistas", 16 de marzo de 1951, AGN, DIPS, 2-1/331.7. vol. 287, exp. 45.

42 "Mitin minero", 17 de marzo de 1951, AGN, DIPS, 2-1/331.7. vol. 287, exp. 45.

43 Ibid, p. 1. 
puede permitir los claudicantes ataques que se les han hecho; que la reforma que ahogó el obscurantismo, y la revolución de 1910 que nos dio libertades, sigue en pie, uniéndose a esa fecha gloriosa, la del 20 de enero de 1951 en que se inició la caravana que todos los componentes de ésta, no van a dejar que se les niegue la justicia[...]". ${ }^{44}$

Los dos siguientes oradores hicieron un relato de la marcha y de los apoyos a lo largo del camino. También hablaron de la necesidad de una justicia real para el grueso de los trabajadores de las minas. ${ }^{45}$

El periódico estadounidense Daily People's Word trató en sus páginas el conflicto minero. El Popular transcribió parte del artículo que había aparecido en Los Ángeles, California:

Después de haber sostenido una huelga de 120 días, los mártires de la zona carbonífera de Nueva Rosita y Cloete, Coahuila, resolvieron marchar en masa a pie, hasta la capital de México en caravana formada por 4,200 trabajadores para protestar ante las autoridades del trabajo por las maniobras puestas en práctica para violar sus derechos. La caravana misma es un heroico ejemplo de conciencia de clase de la clase obrera de México. 1,400 kilómetros de recorrido para mantener los derechos sindicales de todos los trabajadores del país. ${ }^{46}$

Continuaban señalando las aportaciones de dinero que habían sido enviadas desde el extranjero para apoyar a los huelguistas:

La Unión de Mineros de México, la Unión de Mineros de Estados Unidos y de Canadá ha enviado 500 dólares. De muchos países del mundo se ha recibido ayuda solidaria, debido a las informaciones diseminadas por la Federación Sindical Mundial, la cual aportó una suma inicial de 200 dólares. La Unión Internacional de Metalúrgicos 250,000 francos. La Unión Internacional de Mineros con sede en Bruselas 2400 dólares y muchas otras más. Además telegramas y cartas de expresión solidaria se han recibido de todas partes. ${ }^{47}$

44 Idem.

45 Ibid, p. 2.

46 El Popular, 19 de marzo de 1951.

47 Idem. 
En el artículo se exhortaba a los obreros de California a que comprendieran la magnitud de los mineros mexicanos y su responsabilidad económica y moral para con ellos.

El deber de cada miembro de la Unión, no importa a que Unión pertenezca, el de traer este asunto ante los miembros y sus ejecutivos, para que la solidaridad continental sea llevada a la práctica, haciendo donativos de dinero y de cartas y telegramas de adhesión a los mineros que demandan sus derechos. El ayudar a los mineros de México, significa preservar las condiciones que mantienen los mineros de nuestro país y todos los demás obreros. Los dueños de estas minas son las empresas de carbón de Pensylvania, Virginia y demás corporaciones mineras de los Estados Unidos. El ayudar a los mineros de México no sólo es nuestro deber, sino una necesidad para mantener nuestro standard de vida y jornales y condiciones de trabajo que más tarde pueden ser destruidas si los magnates del carbón en México consiguen destruir los derechos de los obreros mineros de México. ${ }^{48}$

Hacia el 28 de marzo los integrantes de la caravana del hambre, estaban muy desmoralizados, no sentían tener un apoyo de los organismos obreros y campesinos del país, sobre todo de la UGOCM, pues esta cada día tenía menos importancia. El presidente Miguel Alemán prácticamente había destruido el movimiento sindical independiente. Lombardo realizaba una labor sindical en el continente latinoamericano y en la Federación Sindical Mundial y ello había originado un descuido en las agrupaciones sindicales del país.

La oficina de investigaciones de la Secretaría de Gobernación destacaba que la mayoría de los integrantes de la caravana se encontraban muy pesimistas y deseaban que la UGOCM les diera su apoyo. Por otra parte, Lombardo se oponía a la terminación de la huelga, ya que los sindicatos petrolero y ferrocarrilero habían sido intervenidos y el gobierno había designado a los dirigentes obreros. ${ }^{49}$

En el periódico El Popular se informó, con fecha de 18 de marzo,

$48 \mathrm{Idem}$.

49 "Informe de la Oficina de Investigaciones Políticas", 24 de marzo de 1951, AGN, DIPS, 2-1/311-7, vol. 288, exp. 9, p. 2. 
que el campamento en que se hallaban instalados los mineros estaba convertido en un campo de concentración porque, además de las patrullas que constantemente vigilaban el sitio, había un gran número de guardias, agentes secretos y granaderos en torno del parque. El Popular señalaba que había vigilancia y cualquier movimiento que pareciera sospechoso a la policía motivaba que inmediatamente se presentaran cientos de agentes. ${ }^{50}$

En el editorial del 20 de marzo, el periódico El Popular, mencionó que desde que se inició el conflicto minero, los trabajadores plantearon una serie de argumentos que nunca fueron rebatidos. El fondo de la argumentación consistió en señalar como causa del conflicto una intromisión indebida e ilegal de las autoridades de la Secretaría del Trabajo, la cual, excediéndose en sus facultades, pretendió imponer a un grupo de dirigentes violentando el estatuto del sindicato y obligando a las empresas a romper el contrato. Se mencionaba igualmente la injerencia de la Junta Federal de Conciliación y Arbitraje que, también violando la ley, dio por no presentado el emplazamiento de huelga de los mineros, si bien este había sido hecho con todos los requisitos legales. ${ }^{51}$

Ni la Secretaría del Trabajo ni la Junta Federal de Conciliación se preocuparon en ningún momento por rebatir los argumentos jurídicos:

La única respuesta oficial a la querella de los mineros fue un tácito reconocimiento de que tenían razón, expresado al concederse a los trabajadores de Palau todo lo que pedían (entendimiento directo de la sección sindical con la empresa, posesión del contrato por la propia sección, tras de haberse revisado para establecer en él los aumentos y prestaciones originalmente pedidos; autonomía en la sección y remisión del conflicto intergremial a una próxima convención nacional). ${ }^{52}$

Un bloque de ocho secciones mineras expidió una declaración relativa a las agrupaciones que participaron en la caravana. Los dirigentes de esta manifestaron públicamente su inconformidad con el fallo emitido por la comisión gubernamental en el conflicto de la región carbonífera y

50 El Popular, 18 de marzo de 1951.

51 Ibid., 26 de marzo de 1951.

52 Ídem., 26 de marzo de 1951. 
consideraron que el dictamen representaba una lesión al derecho de huelga, a la libertad sindical y a los derechos de los mismos huelguistas. ${ }^{53}$ Declaraban:

Como el derecho y principios por los cuales los mineros del carbón son justos, son legales y son humanos, respaldamos su movimiento y estaremos a su lado hasta en tanto se solucionen satisfactoriamente. En virtud de que el conflicto minero representa la lucha de la clase obrera por sus más elementales derechos, haremos un llamado a todas las secciones del sindicato minero y al movimiento obrero en general para que se solidaricen alrededor de la lucha de los mineros carboneros, sin distinción de centrales, discrepancias de credos políticos o religiosos para salvar las conquistas amenazadas. ${ }^{54}$

El 27 de marzo de 1951, un agente de la Secretaría de Gobernación comentaba que los mineros ya habían perdido su trabajo, sus derechos y su antigüedad, habían agotado sus ahorros, vendido casi todas sus pertenencias, perjudicado a sus familiares que sufrían la carencia de recursos económicos. El agente destacaba el cansancio de los mineros que ya querían volver con los suyos. ${ }^{55}$

\section{Comentario final}

La mayor parte de los miembros de la caravana regresaron derrotados a su estado, sin trabajo, algunos buscaron contratación en otras empresas, varios de ellos se convirtieron en pequeños comerciantes. Con la derrota de los mineros culminaba un proceso que rompió los últimos vestigios organizativos e independientes de los sindicatos industriales. Primero, el Estado intervino brutalmente las asociaciones obreras petroleras, luego las ferrocarrileras y, finalmente, doblegó a los mineros inconformes. La estabilidad política, la llegada de las inversiones, la armonía gobiernoempresarios y la inmovilidad y control en los centros laborales favorecían

53 "Piden justicia para los de Rosita los mineros de ocho secciones", El Popular, 26 de marzo de 1951.

54 Idem.

55 "Informe de un agente a la Secretaría de Gobernación", 27 de marzo de 1951, AGN, DIPS, 2-1/331-7, vol. 288, exp. 9. 
en gran parte, lo que el presidente Miguel Alemán llamaba la modernización industrial. El movimiento de la huelga y de la caravana minera representó una de las luchas históricas más relevantes en el país. México crecía económicamente, pero al mismo tiempo los trabajadores eran sometidos. El partido oficial consolidaba su agrupación para gobernar por varias décadas. Se establecieron los pactos obrero-patronales y se subordinó a los sindicatos.

\section{Fuentes}

\section{Archivos}

AGN/Dips Archivo General de la Nación.

Dirección de Investigaciones Políticas y Sociales

\section{Hemerografía}

La Prensa, ciudad de México, 1951.

Excélsior, ciudad de México, 1951.

El Popular, ciudad de México, 1951.

\section{Bibliografía}

Ayala, José, Estado y desarrollo, México, FCE, 1988.

Durán Ponte, Víctor, "Economía, política y sindicatos en los años cuarenta en México", en 75 años de sindicalismo mexicano, México, INEHrM, 1986, pp. 563-584.

Gaitán, Mercedes, El movimiento de los mineros en el alemanismo, México, Instituto de Investigaciones Sociales-UnAm, 1987.

Gill, Mario, La huelga de Nueva Rosita, México, s/e, 1959.

Molina, Daniel, La Caravana del Hambre, México, El Caballito, 1978.

Mussot, María Luisa y Guadalupe González, "En la posguerra. Reestructuración de la CTM y formación de un nuevo proyecto sindical", en Historia de la CTM, 1936-1990, México, UnAm, 1990, pp. 181-251. 
Ortiz Mena, Antonio, El desarrollo estabilizador: reflexiones sobre una época, México, FCE, 1998.

Rivera Castro, José, "Nationalisation et syndicats au Mexique", en Militantisme et histoire, Toulouse, Presses Universitaires, 2000, pp. 275-291.

Santoscoy, María Elena y otros, Breve Historia de Coabuila, México, FCE, 2000. Sariego, Juan Luis y otros, El Estado y la minería mexicana en el siglo XX, México, FCE, 1988.

Vernon, Raymond, El dilema del desarrollo económico en México, México, Diana, 1967. D 